\title{
A Miniature Flow-Through Low Temperature Plasma Ionization Source for Ambient Ionization of Gases and Aerosols
}

\author{
Sandra E. Spencer, Brandon G. Santiago, and Gary L. Glish \\ University of North Carolina at Chapel Hill, Department of Chemistry \\ Chapel Hill, NC, 27599-3290
}

\section{Table of Contents}

Figure S-1: Collision induced dissociation of ions generated from LTPI of ethyl cellulose using the miniature LTP probe with helium as a plasma gas at $m / z$ A. 201 , B. 199 , and C. 183 or with a nitrogen plasma gas at $m / z$ D. 201, E. 199, and F. 183.

Figure S-2: Volatilized caffeine ionized by LTPI in both the conventional and flow-through configuration. 


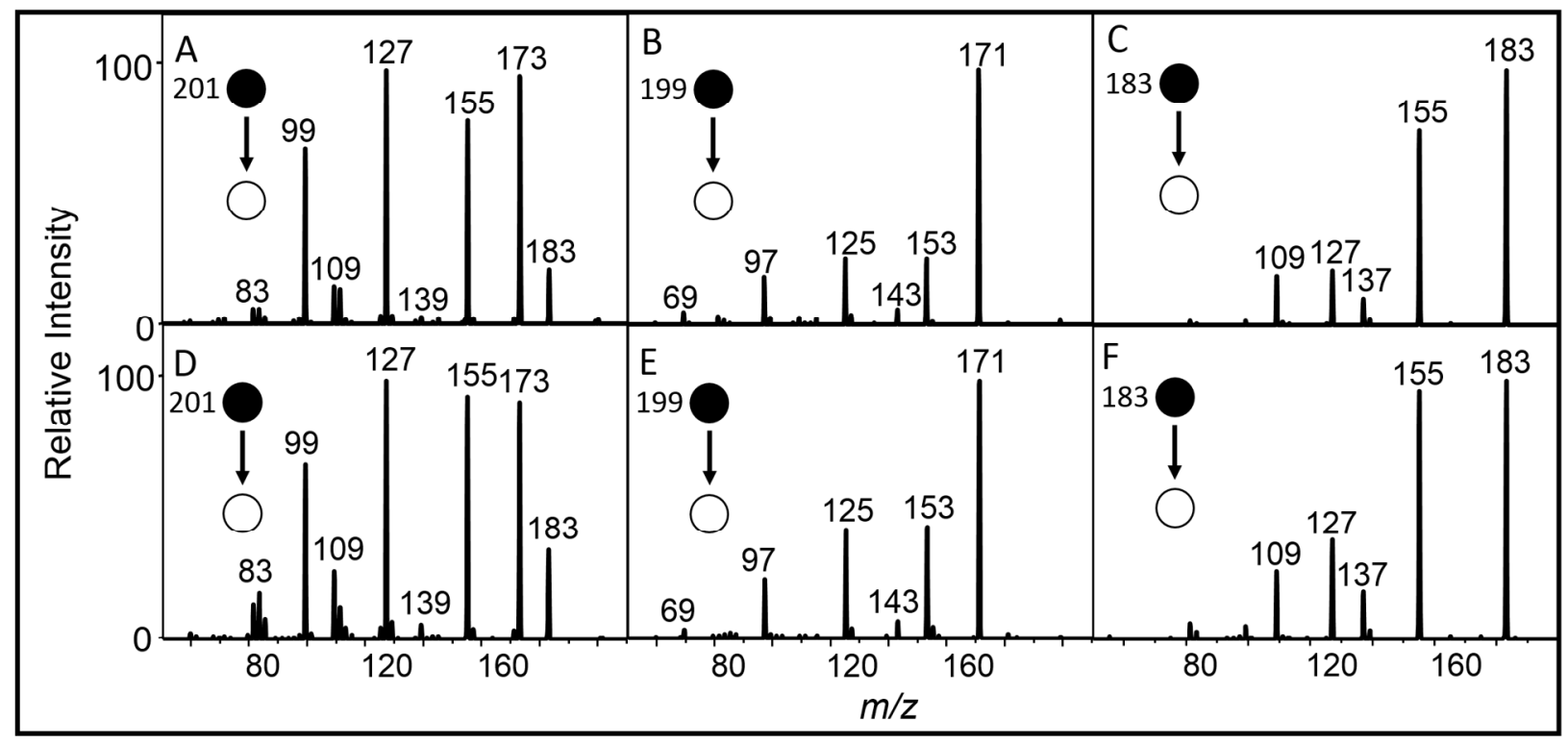

Figure S-1. Collision induced dissociation of ions generated from LTPI of ethyl cellulose using the miniature LTP probe with helium as a plasma gas at $m / z$ A. 201, B. 199 , and C. 183 or with a nitrogen plasma gas at $m / z$ D. 201, E. 199, and F. 183. 


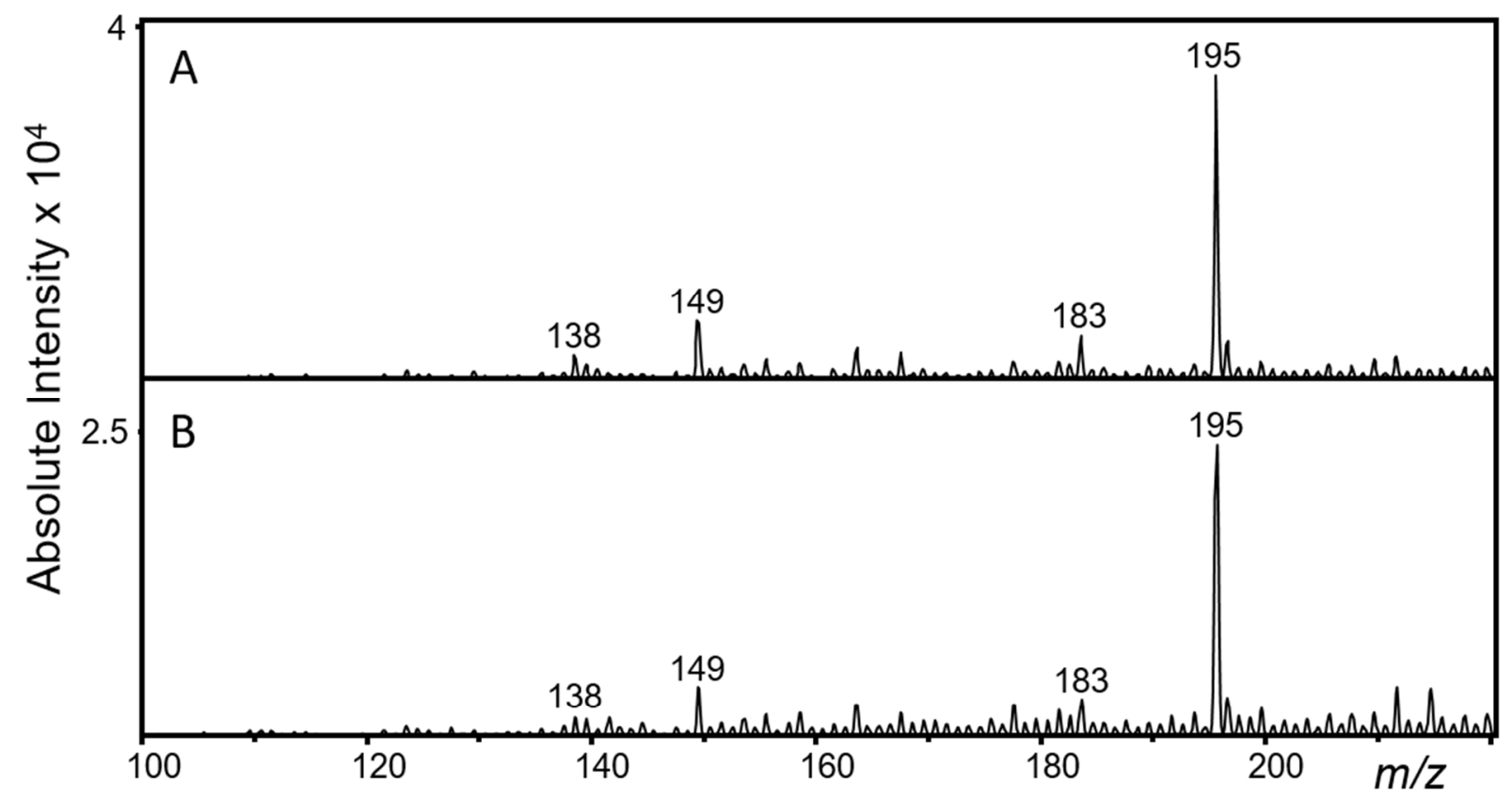

Figure S-2: Volatilized caffeine ionized by LTPI the A. conventional and B. flowthrough configuration. 